\title{
Ultrasonic Tissue Characterization: Techniques of GLHW Study
}

\section{Kazuo Maeda*}

Department of Obstetrics and Gynecology (Emeritus), Tottori University Medical School, Yonago, Japan

The techniques to obtain GLHW using simple B-mode machine is documented in this article, though the summary of GLHW was reported in previous editorial article [1]. Medical ultrasound is superb in the real-time B-mode, transvaginal scan, 3-4D ultrasound, for the morphological diagnosis. Only the Doppler ultrasound is unique in the functional study of blood flow and fetal movement. Although the advanced ultrasound detected the nature of tissue structure in the brightness, back scatter, texture and so on, the results were achieved by advanced computer programs, so that most ultrasound user are out of the benefit of tissue characterization, for example, ovarian malignancy is still diagnosed by the B-mode patterns. The author searched for stable evaluation of the B-mode brightness and found the B-mode brightness histogram prepared in every $\mathrm{B}$-mode machine. However, the mean gray level value changed when the sensitivity was controlled, the contrast of B-mode image changed, and when the subject depth was changed, in the studies with an ultrasound phantom in around 1990. The author then tried the standardization of histogram, and found the histogram base width was stable to the change of device sensitivity. Then the histogram base width was divided byfull length of the brightness to standardize it, and the gray level histogram width (GLHW) value was obtained. As the GLHW was not influenced by the sensitivity control or by the depth of subject, but changed by image contrast, the contrast level was fixed at 2 among multiple levels. The GLHW was stable among various B-mode devices, but a machine was calibrated using ultrasound phantom. Now the GLHW could be applied for the tissue characterization with common B-mode machine without special computer program [2] (Figure 1). The region of interest (ROI) of subject image was $1 \mathrm{~cm}^{2}$ in the study, but found the ROI size did not influence the results. Automatic determination was investigated and confirmed no difference to the manual determination. The automation was introduced into the histogram analysis of Aloka B-mode machine, where the GLHW was expressed by "\%W" sign in Aloka histogram analysis at the same time with mean an SD of simple gray level. The \%W value was utilized in the studies on the fetal lung tissue maturity.

Clinical usefulness of the GLHW is described in the following results obtained in the field of obstetrics, gynecology and perinatology.

\section{The First Trial of GLHW Studies was on Ovarian Benign and Malignant Masses}

Using connecting 5 ROIs of the mass [3], Coefficient of variation

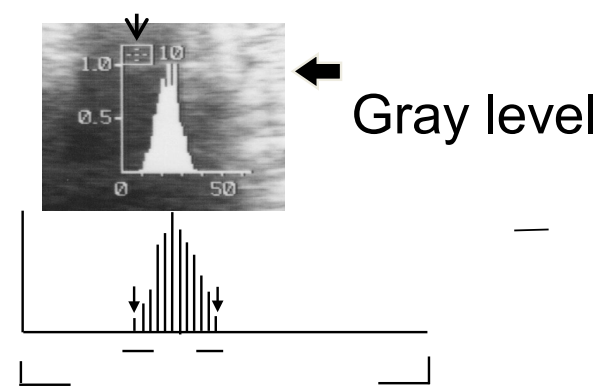

Figure 1: Measurement of GLHW on the monitor screen photo of a B-mode machine.
(CV) was large in benign and small in malignant masses, whereas GLHW was large in malignant and small in benign masses. Both groups were clearly differentiated by the CV and GLHW. The GLHW of ovarian teratoma was between benign and malignant masses (Figure 2).

\section{The GLHW of Endometrial Hyperplasia and Cancer}

The GLHW of endometrial cancer $(58.2 \pm 11.2, \mathrm{~N}=9)$ was significantly larger thanthat of benign endometrial hyperplasia ( 49.6 $\pm 5.0, \mathrm{~N}=4)$ and normal endometrium $(42.7 \pm 3.5, \mathrm{~N}=7)$ (Ito $\mathrm{T})$. The histology may not be needed in such low GLHW case as normal endometrium.Since the GLHW of a uterine cervical cancer mass was higher than 50 [1], malignancy may be screened when the GLHW was larger than 50. Normal adult liver GLHW was measured [3], while hepatic malignancy will be the subject of GLHW study. Placental GLHW was determined in every weeks of pregnancy [3] (Figure 3). GLHW was definitely larger in grade 3 placenta than normal placenta.

The GLHW of a $2^{\text {nd }}$ trimester IUGR was higher than normal placenta, where fibrin deposit in the intervillous space was diagnosed, and afterwardsthe GLHW was returned to normal, estimated fetal weight increased to normal and normal neonate was obtained after the repeated 5,000 $\mathrm{U}$ heparin administration to the mother (Figure 3) whose phospholipid antibody was positive, and the fetus died due to development restriction in previous pregnancy [3].

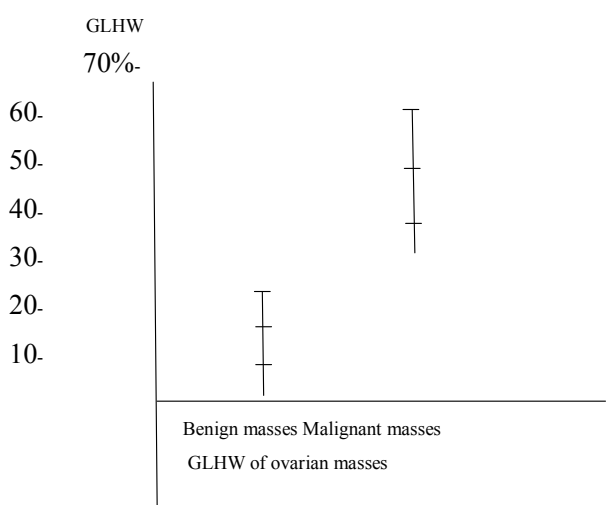

Figure 2: Mean GLHW of 5 connecting ROIs in benign and malignant ovarian masses $[2,3])$.

*Corresponding author: Kazuo Maeda, Department of Obstetrics and Gynecology (Emeritus), Tottori University Medical School, Yonago, 3-125, Nadamachi, Yonago, Tottoriken, 6830835, Japan, Tel: 81-859-22-6856; Fax: 81-859-22-6856; E-mail: maeda@mocha.ocn.ne.jp

Received November 04, 2013; Accepted November 06, 2013; Published November 10, 2013

Citation: Maeda K (2014) Ultrasonic Tissue Characterization: Techniques of GLHW Study. J Health Med Informat. 5: e116. doi:10.4172/2157-7420.1000e116

Copyright: ( 2014 Maeda K. This is an open-access article distributed under the terms of the Creative Commons Attribution License, which permits unrestricted use, distribution, and reproduction in any medium, provided the original author and source are credited. 
Citation: Maeda K (2014) Ultrasonic Tissue Characterization: Techniques of GLHW Study. J Health Med Informat. 5: e116. doi:10.4172/2157$7420.1000 \mathrm{e} 116$

Page 2 of 2

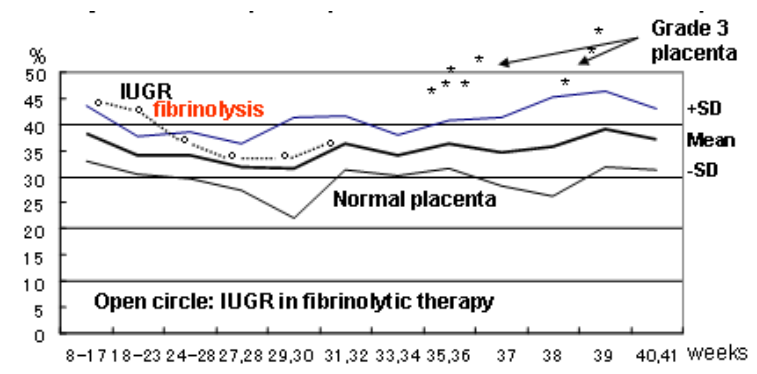

Figure 3: GLHW values of normal placenta and an IUGR case treated with Heparin fibrinolysis under the diagnosis of fibrin deposit in the inter-villous space.
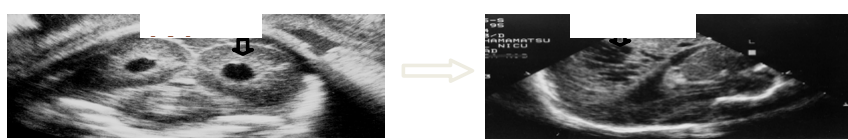

Figure 4: A: The PVE of fetal brain, B: The PVL developed in neonatal brain after $\mathrm{A}$.

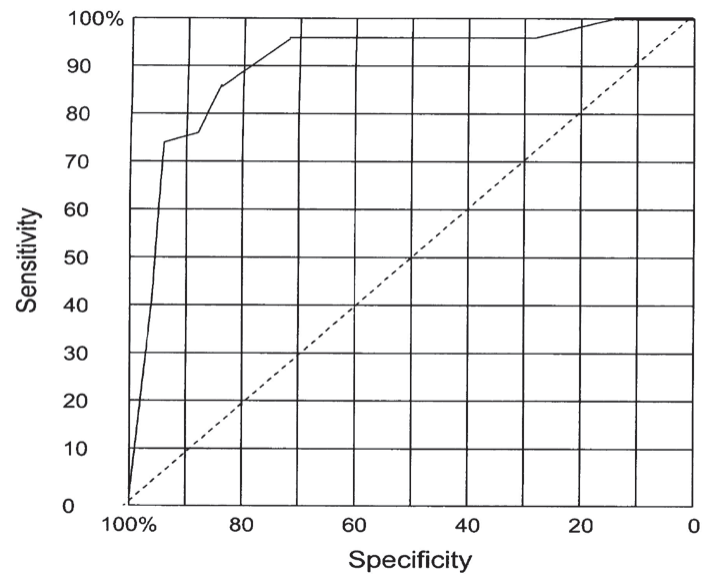

Figure 5: ROC of (GLHW ratio of fetal lung/liver) $\times$ (weeks of pregnancy). The $96 \%$ of neonatal RDS was predicted, if the value was below 29 .

\section{GLHW of Meconium Stained Amniotic Fluid}

Since the GLHW of-the stained amniotic fluidwas similar to the content of fetal colon, and significantly larger than the normal clear amniotic fluid [4], it was suspected that the amniotic fluid was stained by fetal meconium discharged by increased intestinal activity and the loose anal sphincter muscle in fetal hypoxia. Fetal periventricular echodensity (PVE) was a white echogenicperiventriculartissue of fetal brain in B-mode image which was confirmed by higher GLHW than normal brain in the transvaginal scan (Figure 4), and preceded neonatal peri-ventricular leukomalacia (PVL) and cerebral palsy (CP) in 19\% of persisted PVE in preterm fetus until the preterm births [4].

\section{The Immature Fetal Lung Followed by Neonatal Respiratory Distress Syndrome}

(RDS) had been diagnosed by the chemical or physical properties of amniotic fluid obtained by the amniocentesis so far, but the amniocentesis accompanied possible risk of fetal damage or other complications.Recently the immature fetal lung preceding neonatal RDS after birth was correctly diagnosed for $96 \%$ by the GLHW ratio of fetal lung and liverin preterm pregnancy. The ROIs are placed at fetal lung and liver, and the ratio of GLHW values of fetal lung and liver was obtained, then the product of lung and liver GLHW ratio and the weeks of pregnancy was studied.The immature fetal lung to be neonatal RDS was diagnosed when the value was less than 29 with the sensitivity of $96 \%$. The area under curve (AUC) of ROC was 92 (Figure 5) [5]. Since fetal liver GLHW was constant during pregnancy its ratio to fetal lung was a valuable standardization, and also it will delete the inter-device difference of GLHW values.Thus, use of the ratio to fetal liver GLHW is recommended in fetal GLHW investigation. The GLHW study on immature fetal lung is useful because of the same sensitivity as invasive amniocentesis, but also by the protection of the fetus from the risk of invasive amniocentesis, i.e. the GLHW method can be repeated in the same fetus for the monitoring of fetal lung maturity, and for the evaluation of steroid therapy for the preterm fetus. The amniocentesis can be replaced by ultrasonic tissue characterization with GLHW for the diagnosis of fetal lung maturity, asthe non-invasive technique isvery useful in fetal medicine [5].

\section{References}

1. Maeda K (2013) Ultrasonic tissue characterization with common B-mode device: GLHW. J Health Med Informat.

2. Kihaile PE (1989) Ultrasonic tissue characterization of ovarian tumors by the scanning of grey-level histograms. Yonago Acta Medica 32: 251-260.

3. Maeda K, Utsu M, Kihaile PE (1998) Quantification of sonographic echogenicity with grey-level histogram width: a clinical tissue characterization. Ultrasound Med Biol 24: 225-234.

4. Yamamoto N, Utsu M, Maeda K, Serizawa M, Ohki S, et al. (2000) Neonatal periventricular leukomalacia preceded by fetal periventricular echodensity. Fetal Diagn Ther 15: 198-208.

5. Serizawa M, Maeda K (2010) Noninvasive fetal lung maturity prediction based on ultrasonic gry level histogram width. Ultrasound in Med Biol 36: 1998-2003. 